\title{
Enterocolitis, CTCAE
}

National Cancer Institute

\section{Source}

National Cancer Institute. Enterocolitis, CT CAE. NCI Thesaurus. Code C143445.

A disorder characterized by inflammation of the small and large intestines. 